\title{
Haemophagocytic Lymphohistiocytosis as a Complication of Israeli Spotted Fever
}

\author{
Maria Margarida Andrade ${ }^{1}$, Ana Gorgulho ${ }^{1}$, Rita Tinoco Magalhães ${ }^{1}$, Rita Valadas ${ }^{1}$, Luís Miguel Pereira ${ }^{1}$, Sara Freire $^{1}$, Diogo $_{\text {Cruz }}^{1,2}$ \\ ${ }^{1}$ Internal Medicine Department, Hospital de Cascais Dr. José de Almeida, Alcabideche, Portugal \\ ${ }^{2}$ Faculty of Medicine, University of Lisbon, Lisbon, Portugal
}

Received: $21 / 11 / 2021$

Accepted: $29 / 12 / 2021$

Published: $17 / 01 / 2022$

How to cite this article: Andrade MA, Gorgulho A, Magalhães RT, Valadas R, Pereira LM, Freire S, Cruz D. Haemophagocytic lymphohistiocytosis as a complication of Israeli spotted fever. EJCRIM 2022;9: doi:10.12890/2022_003073.

Conflicts of Interests: The authors declare there are no competing interests.

This article is licensed under a Commons Attribution Non-Commercial 4.0 License

\section{ABSTRACT}

Rickettsia spp. human infection is endemic in Portugal in the form of Mediterranean spotted fever caused by R. conorii subsp. conorii and Israeli spotted fever (ISF) caused by R. conorii subsp. israelensis. We describe a rare case of haemophagocytic lymphohistiocytosis (HLH) due to ISF, with atypical manifestations. We highlight the need for clinical suspicion for this diagnosis and the importance of timely intervention and support.

\section{LEARNING POINTS}

- Haemophagocytic lymphohistiocytosis is a rare complication of rickettsiosis.

- An exuberant inflammatory reaction with multisystemic dysfunction should raise suspicion.

- Cutaneous and neurological manifestations can be serious and extensive.

\section{KEYWORDS}

Rickettsiosis, spotted fever, haemophagocytic, purpura fulminans, polyneuropathy

\section{CASE DESCRIPTION}

A 48-year-old healthy male gardener, who had been exposed to dogs and goats but had no recollection of tick exposure, presented to the emergency department with a 6-day course of fever, myalgia, abdominal pain and vomiting. On observation, fever, tachycardia, jaundice, conjunctival erythema, painful hepatosplenomegaly, and confluent maculopapular exanthema that affected the palms and soles were highlighted. Tache noire was not identified.

Blood results showed leucocytosis with $92.5 \%$ neutrophilia, elevated C-reactive protein ( $27.68 \mathrm{mg} / \mathrm{dl})$, thrombocytopenia (45×10\%/l platelets), acute kidney injury, cytocholestasis (total bilirubin $6.88 \mathrm{mg} / \mathrm{dl}$, direct bilirubin $6.56 \mathrm{mg} / \mathrm{dl}$, alanine aminotransferase $103 \mathrm{IU} / \mathrm{l}$, aspartate aminotransferase $266 \mathrm{IU} / \mathrm{I}$, alkaline phosphatase $158 \mathrm{IU} / \mathrm{I}$ and gamma glutamyl transferase (GGT) $246 \mathrm{IU} / \mathrm{I})$, elevated lactate dehydrogenase (769 IU/I), very high ferritin (16,615 $\mathrm{gg} / \mathrm{l})$, fasting triglycerides $29 \mathrm{mg} / \mathrm{dl}$, hyponatremia (123 mmol/I) and hyperlactacidemia. Chest x-ray showed no abnormalities, while abdominal ultrasound revealed a homogeneous hepatosplenomegaly. Blood and urine cultures were drawn, as well as blood for multiple pathogen serologies, and intravenous doxycycline $100 \mathrm{mg} 12 / 12 \mathrm{~h}$ was started empirically.

On the next day, mental confusion, respiratory distress and refractory hypotension required admission to the intensive care unit (ICU) and vasoactive therapy. There was also acute anaemia ( $\mathrm{Hb} 8 \mathrm{~g} / \mathrm{dl})$ and worsening of thrombocytopenia $\left(20 \times 10^{\%} / / \mathrm{platelets}\right)$, triglycerides increased to $405 \mathrm{mg} / \mathrm{dl}$ and ferritin levels to $20,868 \mu \mathrm{g} / \mathrm{dl}$. Transfusion support with a platelet pool was required. Skin lesions became dusky, necrosis appeared and there was extensive desquamation (Fig. 1). 
Four days later, vasoactive therapy was discontinued, sustained apyrexia was noted and there was no need for oxygen supplementation. Two days later, neuropathic pain started in both lower limbs, with insensitivity to pain and defects in the deep sensitivity of the left foot. The patient completed 7 days of antibiotic therapy with a favourable clinical and analytical response, maintaining only skin lesions in slow but progressive improvement. After 20 days of hospitalization, he was discharged and referred to a rehabilitation centre.

Blood and urine cultures were negative as were serologies for cytomegalovirus, human immunodeficiency virus, hepatotropic viruses, herpes viruses, Brucella, Coxiella, Leptospira and Leishmania. Despite negative Rickettsia serologies, the polymerase chain reaction for Rickettsia spp. DNA in the blood was positive, which molecular characterization identified as $R$. conorii israelensis.

The skin biopsy confirmed the existence of leucocytoclastic vasculitis (Fig. 2). General wound management measures were maintained, with no infectious complications. The electromyogram showed axonal sensory polyneuropathy of the lower limbs. Neuropathic pain was controlled with pregabalin.

At discharge, new serologies were collected which were positive for $R$. conorii (IgM 1/48 and IgG 1/320).

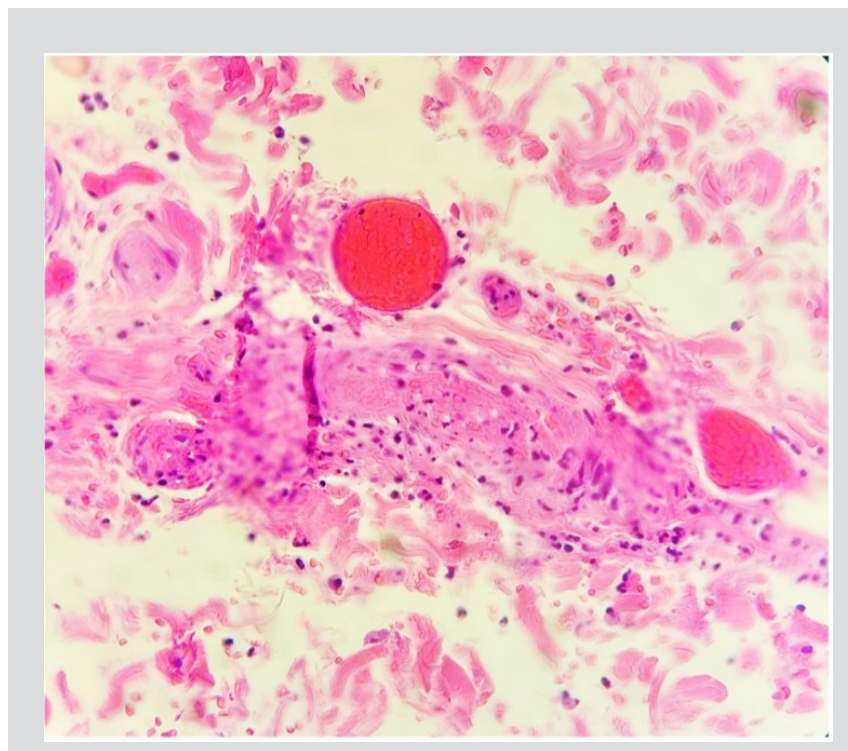

Figure 2. Leucocytoclastic vasculitis with fibrinoid necrosis and infiltration of the vascular wall by lymphocytes and neutrophils in the deep dermis 


\section{DISCUSSION}

Haemophagocytic lymphohistiocytosis $(\mathrm{HLH})$ is an aggressive and life-threatening syndrome of excessive inflammation that is categorized as primary (familial) or secondary (acquired). Primary HLH is mostly caused by recessive genetic mutations affecting the cytotoxic function of T lymphocytes and natural killer cells. It typically presents in young children in the first year of life with or without a positive family history ${ }^{[1]}$. Secondary HLH appears in the setting of infections (viral, bacterial, fungal or parasitic), malignancy (mostly non-Hodgkin lymphoma and acute leukaemia), rheumatological diseases (such as adult-onset Still disease, systemic juvenile idiopathic arthritis, and systemic lupus erythematosus) or metabolic conditions ${ }^{[1,2]}$. Despite HLH being well described in the paediatric population, its incidence in adults is unknown notwithstanding the number of cases reported in the literature dramatically increasing over the past 10 years ${ }^{[1]}$.

$\mathrm{HLH}$ can occur as the initial presentation of an underlying disorder or later in the disease course, occasionally in the setting of progression or in the presence of an additional trigger. Due to the non-specific symptoms, clinical suspicion for this diagnosis and a timely intervention and support are crucial ${ }^{[2,3]}$. The diagnostic criteria (Table 1) were developed for the diagnosis of paediatric HLH but have been widely applied to patients with secondary $\mathrm{HLH}$, including adults as there is currently no commonly accepted set of criteria for diagnosing HLH in the adult population ${ }^{[1]}$.

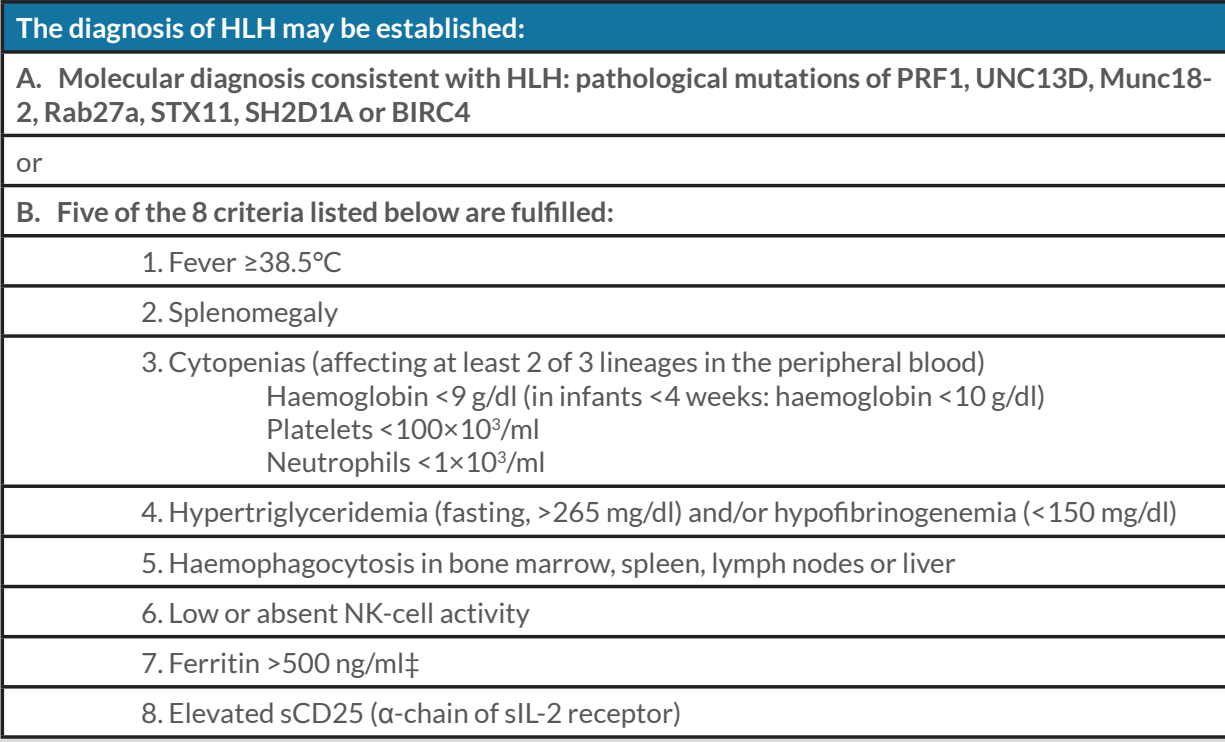

Table 1. Diagnostic criteria for haemophagocytic lymphohistiocytosis (HLH) used in the HLH-2004 trial $^{[1]}$

$\ddagger$ Although the HLH-2004 protocol uses ferritin $>500 \mathrm{ng} / \mathrm{ml}$, we generally view ferritin $>3000 \mathrm{ng} / \mathrm{ml}$ as concerning for $\mathrm{HLH}$ and ferritin $>10,000$ as highly suspicious $^{[1]}$

The treatment of $\mathrm{HLH}$ is designed to halt any underlying trigger and control the overactive immune system. If a malignancy, rheumatological disorder or infection is identified, disease-specific treatment should be started immediately with an etoposide chemotherapy regimen, corticotherapy or antibiotic therapy, respectively ${ }^{[1,2]}$. These measures are occasionally sufficient to stop the immune dysregulation. Additional immunosuppressive therapy should be initiated immediately in severe cases, familial disease cases and in those who fail to respond to disease-specific therapy after $2-3$ days ${ }^{[1]}$. The mortality of secondary HLH in adults without treatment is high (50-75\%), but the statistics are limited by the small number of cases ${ }^{[1]}$.

Spring and summer provide the perfect conditions for human infection by Rickettsia spp., which is endemic in Portugal, with the incidence of atypical and severe forms increasing, manifesting with multi-organ dysfunction and vasculitic phenomena ${ }^{[2]}$. These are attributed to the affinity of Rickettsia spp. for endothelial cells with resultant vasculitis. There are three case reports of $R$. conorii subsp. israelensis infection and purpura fulminans ${ }^{[4]}$ and one of $\mathrm{HLH}^{[2]}$.

Even though there are several overlapping features in both syndromes and distinguishing them can be difficult (Table 2), the authors believe that the patient presented with spotted fever and then developed HLH. At the time of admission to the emergency department, the patient already had had non-specific symptoms for 6 days, which had been gradually worsening. At the time of his first clinical and analytical evaluation, he only presented fever, hepatosplenomegaly, elevation of inflammatory parameters, rash, thrombocytopenia, hyponatremia, elevations in serum aminotransferases and bilirubin and acute kidney injury, not meeting HLH criteria. However, a zoonosis was considered, namely Rickettsia spp. infection, and treatment was promptly initiated. There was rapid evolution to dysfunction of the central nervous system (CNS) with confusion, fluid refractory hypotension and respiratory failure, and anaemia, while serum triglycerides increased to 405 


\begin{tabular}{|c|c|c|}
\hline & Israeli spotted fever & $\begin{array}{l}\text { Hemophagocytic } \\
\text { lymphohistiocytosis }\end{array}$ \\
\hline $\begin{array}{l}\text { Non-specific signs and symptoms } \\
\text { (headache, myalgias, arthralgias, abdomi- } \\
\text { nal pain) }\end{array}$ & Yes & Yes \\
\hline Fever & Yes & Yes \\
\hline $\begin{array}{l}\text { Elevation of inflammatory parameters and } \\
\text { hypofibrinogenemia }\end{array}$ & No & Yes \\
\hline Ferritin $>500 \mu \mathrm{g} / \mathrm{l}$ & No & Yes \\
\hline $\begin{array}{l}\text { CNS involvement (confusion, seizures) and } \\
\text { PNS involvement (polyneuropathy) }\end{array}$ & $\begin{array}{l}\text { Yes } \\
\text { PNS involvement is rare }\end{array}$ & $\begin{array}{l}\text { Yes } \\
\text { PNS involvement is rare }\end{array}$ \\
\hline $\begin{array}{l}\text { Cardiovascular involvement (hypotension, } \\
\text { hyperlactacidemia) }\end{array}$ & Yes & Yes \\
\hline Conjunctival erythema & Yes & No \\
\hline Cutaneous manifestations & Yes & Yes \\
\hline Purpura fulminans & Yes & No \\
\hline Respiratory distress syndrome & No & Yes \\
\hline Cytopenias $\geq 2$ lineages & $\begin{array}{l}\text { No } \\
\text { Usually, only thrombocytopenia }\end{array}$ & Yes \\
\hline Coagulation abnormalities & No & Yes \\
\hline Haemophagocytosis & No & Yes \\
\hline Hypofibrinogenemia & No & Yes \\
\hline Hyponatremia & Yes & Yes \\
\hline $\begin{array}{l}\text { Hypertriglyceridemia and increased very } \\
\text { low-density lipoprotein }\end{array}$ & No & Yes \\
\hline $\begin{array}{l}\text { Elevations in serum aminotransferases } \\
\text { and bilirubin }\end{array}$ & Yes & Yes \\
\hline Elevated GGT & No & Yes \\
\hline Acute renal failure & Yes & Yes \\
\hline Hepatosplenomegaly & Yes & Yes \\
\hline
\end{tabular}

Table 2. Comparison between clinical and analytical characteristics of Israeli spotted fever (ISF) and haemophagocytic lymphohistiocytosis $(\mathrm{HLH})^{[1,3-5]}$

CNS, central nervous system; GGT, gamma glutamyl transferase; PNS, peripheral nervous system.

$\mathrm{mg} / \mathrm{dl}$ and ferritin levels to $20,868 \mu \mathrm{g} / \mathrm{dl}$, meeting five of the eight criteria accepted for HLH. Also, the GGT level is a particularly sensitive marker to monitor because of biliary tract infiltration by lymphocytes and macrophages ${ }^{[2]}$.

Like HLH, multiple organ dysfunction syndrome (MODS) can affect any organ system, and there may be some overlap between these diagnoses. An extremely high ferritin or dramatically increasing ferritin level is more consistent with HLH than with MODS. Elevated ferritin occurs in most patients with HLH but is non-specific ${ }^{[1]}$; its source is thought to be macrophages, which are extensively recruited in these situations. The published criteria use a ferritin cut-off value of $\geq 500 \mu \mathrm{g} / \mathrm{l}$, but recent studies in the paediatric population have demonstrated that a higher threshold of $\geq 10,000 \mu \mathrm{g} / \mathrm{l}$ has $90 \%$ sensitivity and $96 \%$ specificity for $\mathrm{HLH}^{[3]}$; however, in adults it seems to be less specific.

Since the evolution was favourable with antibiotic therapy after a short period of time, with rapid resolution of organ dysfunctions allowing the withdrawal of support measures, in the absence of recurrence, no other medications were administered or invasive examinations performed. Further studies will be needed to clarify the role of $R$. conorii subsp. israelensis infection in the development of HLH ${ }^{[2]}$.

Atypical manifestations were noted in this clinical case. The peripheral nervous system (PNS) involvement with the presence of axonal sensory polyneuropathy of the lower limbs favours the hypothesis of direct nerve injury by the microorganism, probably due to vasculitis of the vasa nervorum ${ }^{[5]}$. The extensive cutaneous involvement with lesions compatible with purpura fulminans is not a typical feature of ISF. The severe and confluent skin lesions undoubtedly contribute to bloodstream infections, leading to death in previous case reports. This is a potentially misleading manifestation of ISF that must be recognized and treated in a timely fashion ${ }^{[1]}$. 


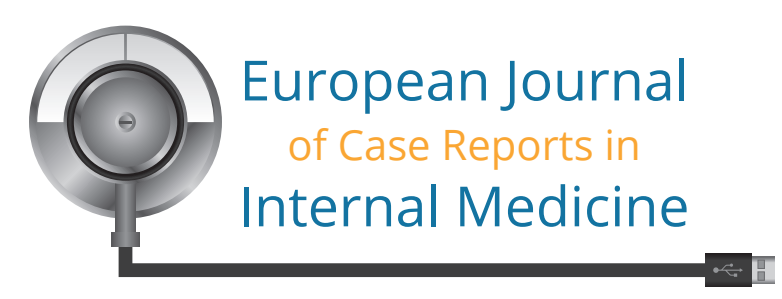

To the best of our knowledge, this case report presents the second patient with HLH due to ISF. Clinicians should recognize the characteristic clinical picture, be alert to complications, and act accordingly in the face of multiorgan dysfunction. We highlight the rarity of cutaneous and neurological complications.

\section{REFERENCES}

1. Schram A, Berliner N. How I treat hemophagocytic lymphohistiocytosis in the adult patient. Blood 2015;125(19):2908-2914.

2. Pérez-de Pedro I, Macías-Vega N, Miranda-Candón I, Teresa Camps-García M. Infección grave por Rickettsia conorii asociada a síndrome hemofagocítico. Enferm Infecc Microbiol Clín 2008;26(9):597-598.

3. Wu JR, Yuan LX, Ma ZG, Chen XX, Gu L, Gao J. GDF15-mediated upregulation of ferroportin plays a key role in the development of hyperferritinemia in children with hemophagocytic lymphohistiocytosis. Pediatr Blood Cancer 2013;60(6):940-945.

4. Cohen R, Babushkin F, Shapiro M, Uda M, Atiya-Nasagi Y, Klein D, et al. Two cases of Israeli spotted fever with purpura fulminans, Sharon District, Israel. Emerg Infect Dis 2018;24(5):835-840.

5. Evangelista T, Pimentel J, Luis M de L. Polirradiculonevrites agudas associadas à febre escaro-nodular [Acute polyradiculoneuritis associated with boutonneuse fever]. Acta Med Port 1994;7(7-8):437-439. 